\title{
Modo Enunciativo e a Modalização em Memórias de Emília de Monteiro Lobato
}

\author{
Jussara Maria Leão Coelho AMARAL@ (1) \\ Centro Federal de Educação Tecnológica de Minas Gerais (CEFET-MG)
}

RESUMO

Neste artigo, tendo como corpus diálogos extraídos da obra Memórias de Emília, de Monteiro Lobato, buscamos analisar os diferentes tipos de relações de influência a partir do comportamento enunciativo da boneca com as personagens Visconde, anjinho e tia Nastácia, por meio dos processos de modalização, e identificar os posicionamentos do autor diante de alguns temas candentes. Os dados foram analisados à luz da Teoria Semiolinguística, de Charaudeau (2010), o que nos permitiu reconhecer, na voz

○

OPEN ACCESS

EDITADO POR

- Raquel Freitag (UFS)

AVALIADO POR

- Evangelina Maria Brito de Faria (UFPB)

- Lucas Nascimento (UFRJ)

DATAS

- Recebido: 05/05/2020

- Aceito: 25/07/2020

- Publicado: 12/08/2020

COMO CITAR

Amaral, J. M. L. C. (2020)

Modo Enunciativo e a Modalização em Memórias de Emília de Monteiro Lobato. Revista da Abralin, v. 19, n. 1, p. 1-23, 2020. da Emília, associada ao contexto histórico-social do autor, valores preconizados pela voz ficcional de Lobato. Por meio da sua postura adulta, ela questiona os valores do capitalismo e reforça estereótipos da raça negra. Desse modo o autor desmistifica o estereótipo de bondade e inocência infantil e apresenta uma criança mais próxima da realidade: contestadora, voluntariosa, e, às vezes, até cruel. Vale ressaltar a genialidade do autor ao materializar tudo isso pela fala de uma boneca.

\section{ABSTRACT}

In this article, having as corpus some dialogues extracted from the work Memórias de Emília, by Monteiro Lobato, we aim at analyzing the different types of influence relationships based on the enunciative behavior of the doll with the characters Visconde, anjinho and aunt Nastácia through the processes of modalization and identify the author's positions in relation to some burning themes. The data were analyzed in the light of Charaudeau's Semiolinguistic Theory (2010), which allowed us to recognize, in Emília's voice, associated with the author's historical-social context, values 


\section{REVISTA DA ABRALIN}

advocated by Lobato's fictional voice. Through her adult stance, she questions the values of capitalism and reinforces the black race. In this way the author demystifies the stereotype of kindness and childlike innocence and presents a child closer to reality: defiant, willful, and sometimes even cruel. It is worth mentioning the genius of the author to materialize all this through the speech of a doll.

\section{PALAVRAS-CHAVE}

Análise do discurso. Comportamento Enunciativo. Modalização. Texto literário.

\section{KEYWORDS}

Discourse analysis. Enunciative Behavior. Modalization. Literary text.

\section{Introdução}

Este estudo, parte da minha pesquisa de mestrado, ${ }^{1}$ aborda tanto aspectos literários quanto linguísticos, pois elegemos, como corpus, diálogos entre Emília e as demais personagens, Visconde, tia Nastácia e anjinho², na obra Memórias de Emília, de Monteiro Lobato, que serão analisados a partir da concepção do Modo Enunciativo e, particularmente, da Modalização proposta por Charaudeau (2010).

Para esse autor, a modalização é uma categoria à qual correspondem os meios de expressão que explicitam as diferentes posições do falante e suas intenções enunciativas. À luz dessa abordagem, buscamos (i) avaliar as estratégias que revelam o comportamento enunciativo de Emília a partir da análise dos diferentes tipos de relações de influência da boneca sobre as outras personagens, por meio dos processos de modalização, e (ii) identificar posicionamentos do autor que parecem ser vocalizados por essa personagem.

Assim sendo, para analisar as estratégias enunciativas encenadas no âmbito dessa ficção lobatiana, foi necessário um segundo recorte no corpus, a partir da seleção de diálogos da boneca com seus vários interlocutores. Por essa razão foram selecionados apenas os diálogos realizados em discurso direto, considerando que a obra possui um narrador em terceira pessoa e que os personagens Emília e Visconde se transformam, cada um a seu tempo, em enunciadores importantes.

\footnotetext{
1 Dissertação intitulada O comportamento enunciativo de Emília na obra "Memórias de Emília", de Monteiro Lobato, por meio dos processos de modalização, defendida em 09.12.2015, sob orientação da professora Ana Maria Nápoles Villela e coorientação do professor Luiz Henrique Silva de Oliveira, no Programa de Pós-Graduação em Estudos de Linguagens, do Centro Federal de Educação Tecnológica de Minas Gerais - CEFET-MG
}

2 Os nomes próprios serão transcritos conforme estão no livro Memórias de Emília. 


\section{REVISTA DA ABRALIN}

Sendo Emília a personagem principal da obra Memórias de Emília, pode-se perceber que ela tem papel fundamental não somente na construção das interações que movimentam a narrativa, mas, também, na própria natureza da construção das conversas, o que aponta para as relações de influência que ela estabelece com seus interlocutores.

\section{O criador e a criatura}

A trajetória de sucesso de Lobato é descrita por Zilberman (2010) que revela o percurso da carreira do autor, começando com a publicação dos dois artigos Velha Praga e Urupês, ambos publicados no Jornal Estado de São Paulo, de 1914, que lhe rendem fama e sucesso. A partir dessas publicações, cria um dos seus personagens que o consagraram na vida literária: o Jeca Tatu.

Insatisfeito com a vida de fazendeiro e diante de toda essa fama, decide vender a fazenda $\mathrm{Bu}$ quira e mudar-se para São Paulo onde, em 1918, compra a Revista do Brasil.

Em 1921, publica, pela primeira vez, o livro O Saci, cujo personagem principal é caracterizado por meio de traços infantis e posturas brincalhonas. O êxito comercial fortalece o desejo de sucesso com seus livros e leva-o a publicar também textos de seus amigos como Godofredo Rangel, Ricardo Gonçalves e Waldomiro Silveira. Mas, entre um sucesso e outro, Lobato demonstra, em cartas ao seu amigo Godofredo Rangel, "[...] os impasses, indecisões, escrúpulos e sustos de um escritor transvestido de editor [...]" (LAJOLO, 2000, p. 31), que começa a compreender a literatura também como mercadoria.

Homem preocupado com o progresso do Brasil e extremamente interessado nos problemas sociais, acreditava no poder das ideias e, como escritor, não mediu esforços para propagar seu projeto modernizador para o país. Segundo a pesquisadora, "a base do projeto lobatiano está diretamente ligada à tomada de consciência do escritor, ao perceber a miséria do interior brasileiro, e ao desejo de se tornar um agente de mudança do país." (DINIZ, 1998, p. 126).

Monteiro Lobato, por ser um homem inteligente, tinha consciência da força transformadora da leitura em uma sociedade carente de saber, e acreditava que uma das formas de levar o país a crescer, tornar-se próspero e desenvolvido seria o investimento na educação, portanto preocupava-se em tornar a aquisição do conhecimento um ato prazeroso. Assim, o autor procurava instruir, mas, ao mesmo tempo, divertir seus pequenos leitores com histórias fascinantes que despertavam a curiosidade e, principalmente, o interesse pela leitura.

Perspicaz e audacioso, vê o investimento no público infantil como uma grande oportunidade de negócios e começa a escrever para esse segmento até então ignorado. Transfere o sucesso e o knowhow com livros não infantis para o gênero infantil e publica, em 1921, sua mais nova e próspera invenção: o Sítio do Picapau Amarelo, com o lançamento do livro A menina do narizinho arrebitado.

Nessa primeira história, criou sua personagem de maior destaque, a boneca Emília, que nasceu muda, mas, com a ajuda da pílula falante, transforma-se de uma bruxa em uma boneca falante. Lajolo 


\section{REVISTA DA ABRALIN}

(2001) caracteriza-a como personagem híbrida e mestiça que, ao mesmo tempo, por meio da fala, transcende sua condição de ser inanimado. Por essa razão Emília goza de mais liberdade do que qualquer outro personagem, o que lhe permite viver o que há de melhor nos dois mundos - real e fictício - e fecundar um com o ponto de vista do outro. Sousa (2009) corrobora essa análise de Lajolo, pois considera que Emília:

[...] não é boneca, nem ser humano; não é adulto, nem criança; não é má como uma bruxa, nem bondosa como uma fada, mas tudo isso ao mesmo tempo -, as crianças se identificam com ela e é nela que espelham seus anseios e desejos, é nela que objetivam sua situação psicológica, social e até mesmo intelectual. Por isso Emília é tão querida, não só por crianças, como por adultos, que assim como seu criador se divertem com suas diabruras, seu atrevimento e sua "torneirinha de asneiras". (SOUSA, 2009, p. 86).

Ainda de acordo com Sousa (2009, p. 88), Emília pode ser vista como um "instrumento do projeto nacionalista e popular de Monteiro Lobato" para uma sociedade pensante, contestadora, inconformada, aberta a novas ideias e teorias. A criança, nesse projeto, é vista por ele como um suporte de desenvolvimento social capaz de conduzir o Brasil ao tão sonhado progresso. Essa personagem, ao adquirir essa capacidade de falar, rompe com o estereótipo de criança educada e bem comportada, começa a questionar as verdades estabelecidas, a expor seus pontos de vista, o que viola e desafia os padrões sociais da época, comportamento considerado inadequado, mas que fascinava e desafiava os leitores. Prova disso são as interações entre Emília e determinados personagens, tais como anjinho, Visconde e tia Nastácia, conforme poderemos ver adiante.

Na literatura sobre a obra de Monteiro Lobato, vários críticos referem-se à personagem Emília como sendo seu alter ego ${ }^{3}$. Na análise de Coelho "a cada novo livro, mais e mais se afirma a personalidade livre e voluntariosa de Emília, até que se transforma em verdadeiro alter-ego do autor; em irreverente porta-voz de suas idéias libertárias e progressistas." (COELHO, 1984, p. 730). Esses críticos consideram que, muitas vezes, opiniões que contrariavam o senso comum da época eram colocadas na boca da boneca para que ela pudesse ser porta voz de problemas sociais.

Antônio (2005) faz uma análise das principais características da personagem classificando-a como sendo redonda, por apresentar uma caracterização, mais detalhada, quanto a aspectos físicos, sociais, ideológicos, morais e psicológicas.

[...] resume o que Lobato gostaria de repassar para a humanidade enquanto escritor. É por meio dessa personagem que se ouvem os seus protestos. Com Emília, Monteiro Lobato grita independência ou morte, mostrando um pouco de si, isto é, determinado e teimoso, mas com um belo coração, um coração cheio de sonhos, um coração que sofre diante dos dissabores da vida. (ANTÔNIO, 2005, p. 26).

3 Pesquisadores que consideram Emília o alter-ego do autor: Marisa Lajolo, Nelly Novaes Coelho, Neide Medeiros Santos, entre outros. 


\section{REVISTA DA ABRALIN}

A autora conclui afirmando que "a personagem Emília representa o verdadeiro Monteiro Lobato. Com essa personagem, o autor mantém-se imortal, incomodando ainda muita gente, pois Lobato ou Emília diz tudo o que pensa, agrade ou não." (ANTÔNIO, 2005, p. 39).

Além desses, muitos outros trabalhos investigam especificamente a boneca Emília e foram de especial importância para corroborar os objetivos desta pesquisa.

\section{Embasamento teórico}

Nesta seção, serão apresentados o Modo Enunciativo e a Modalização, acompanhados das análises de diálogos ${ }^{4}$ de Emília extraídos da obra Memórias de Emília, pois é a partir do estudo do uso da modalização, ou seja, dos índices de subjetividade, que poderemos investigar de que maneira Lobato, por meio da encenação das conversas entre a boneca e as demais personagens, posiciona-se diante de alguns temas polêmicos na época.

\subsection{O modo enunciativo}

O Modo Enunciativo, segundo Charaudeau, "[...] é uma categoria de discurso que aponta a maneira por meio da qual o sujeito falante age na encenação do ato de comunicação [...]" (CHARAUDEAU, 2010, p. 81). Ele é responsável por situar a posição do sujeito falante em relação ao seu interlocutor, em relação ao que ele e os outros dizem. Isso permite distinguir três funções desse modo que são:

i) estabelecer uma relação de influência entre locutor e interlocutor num comportamento ALOCUTIVO;

ii) revelar o ponto de vista do locutor, num comportamento ELOCUTIVO;

iii) retomar a fala de um terceiro, num comportamento DELOCUTIVO. (CHARAUDEAU, 2010, p. 82).

4 Dado o limite de espaço, foram extraídos da dissertação apenas alguns exemplos. Para aprofundamento da análise de todos os diálogos ver: <https://sucupira.capes.gov.br/sucupira/public/consultas/coleta/trabalhoConclusao/viewTrabalhoConclusao.jsf?popup=true\&id_trabalho=3353772\# > Acesso em: 15.04.2020. 


\section{REVISTA DA ABRALIN}

O comportamento alocutivo visa a estabelecer uma relação de influência entre locutor e interlocutor, enunciando sua posição em relação ao outro e impondo um determinado comportamento. O interlocutor, por meio da linguagem, é solicitado a ter uma determinada reação: responder e/ou reagir (relação de influência), como comprova o exemplo do corpus “- Visconde - disse ela - venha ser meu secretário. Veja papel, pena e tinta. Vou começar as minhas Memórias." (LOBATO, 1994a, p. 8). Nesse momento, Visconde é chamado para atender a um pedido de Emília.

O sujeito falante ainda atribui papéis linguageiros a si e ao seu interlocutor, enunciando: (i) uma posição de inferioridade em relação ao interlocutor, uma vez que necessita do "saber" e do "poder fazer" do interlocutor, estabelecendo-se uma relação de petição e (ii) uma posição de superioridade em relação ao interlocutor, impondo uma ação a fazer, o que estabelece uma relação de força, demonstrada pelas modalidades de injunção, interpelação, autorização, aviso, julgamento, sugestão e proposta. É o caso das modalidades de Interrogação e de Petição, como mostra a passagem a seguir em que Emília, procurando ensinar ao anjinho sobre as coisas mundanas, perguntava: “_ "Árvore, sabe o que é?" (LOBATO, 1994a, p. 12). Ao fazer essa pergunta, a boneca atua como professora, detentora do "saber", colocando-se em uma posição de superioridade e usa sua didática para introduzir um tema específico.

No comportamento elocutivo, o objetivo do locutor é expor seu ponto de vista, sem implicar o interlocutor em uma tomada de posição. De acordo com Charaudeau, "O resultado é uma enunciação que tem como efeito modalizar subjetivamente a verdade do Propósito enunciado, revelando o ponto de vista interno do sujeito falante." (CHARAUDEAU, 2010, p. 83). Um exemplo desse comportamento pode ser representado pela passagem: “- Bem. Nasci, fui enchida de macela que todos entendem e fiquei no mundo feito uma boba, de olhos parados, como qualquer boneca. E feia. Dizem que fui feia que nem uma bruxa." (LOBATO, 1994a, p. 10). Ao usar essa modalidade, a protagonista constata a realidade dos fatos, ao mesmo tempo em que discute sua própria identidade, a partir de posicionamento e visão do outro, por considerá-la boba, feia e bruxa. Sendo assim, parece que uma das formas que a boneca encontrou para lutar contra essa imagem foi, provavelmente, adquirindo um posicionamento incisivo para silenciar opiniões alheias. As categorias que especificam o ponto de vista do locutor são:

i) Modo de saber - especifica como o locutor tem conhecimento de um Propósito. Fazem parte desta categoria as modalidades de "Constatação" e de "Saber/Ignorância". Como exemplo desta primeira modalidade podemos citar: "- Cabo é uma perna só por onde a gente segura. Faca tem cabo. Garfo tem cabo. Bule tem cabo (e bico também). [...]” (LOBATO, 1994a, p. 13). E, de saber/ignorância: “- É que o começo é difícil, Visconde. Há tantos caminhos que não sei qual escolher. Posso começar de mil modos. Sua ideia qual é?" (LOBATO, 1994a, p. 10).

ii) Avaliação - especifica a maneira como o sujeito julga o Propósito enunciado. Correspondem às modalidades de "Opinião" e de "Apreciação". Como exemplo da categoria modal de apreciação, transcrevemos parte de um diálogo com 


\section{REVISTA DA ABRALIN}

anjinho "[...] - O cão é um colosso. Pois bem. Quando um homem compara outro homem ao cão, dizendo 'Tu és um cão', o outro puxa faca. Desaforo é isso..." (LOBATO, 1994a, p. 13-14).

iii) Motivação - especifica a razão pela qual o sujeito é levado a realizar o Propósito enunciado. Corresponde às modalidades de "Obrigação", "Possibilidade" e "Querer". A categoria modal de possibilidade aparece no enunciado "- Contou que fui eu quem salvou tudo? Que se não fosse a minha ideia da couve a situação teria sido um horror?" (LOBATO, 1994a, p. 42).

iv) Engajamento - especifica o grau de adesão ao Propósito. Corresponde às modalidades de "Promessa", "Aceitação"/Recusa", "Acordo/Desacordo", "Declaração". O diálogo a seguir entre Emília e Visconde pode ser identificado como exemplo de desacordo:

“- Por que tanta estrelinha? Será que quer ocultar a idade?

- Não. Isso é apenas para atrapalhar os futuros historiadores, gente muito mexeriqueira. Continue escrevendo: E nasci duma saia velha de tia Nastácia. [...]”. (LOBATO, 1994a, p. 10).

v) Decisão - especifica tanto o estatuto do locutor quanto o tipo de decisão que o ato de enunciação realiza. Corresponde à modalidade de "Proclamação." No corpus analisado, não identificamos nenhuma categoria modal de Proclamação.

No comportamento delocutivo, o locutor retoma a fala de um terceiro, apagando-se e não implicando o seu interlocutor. Nesse caso, os interlocutores estão ausentes no ato de enunciação, razão pela qual as declarações são expressas de modo impessoal ou referem-se à terceira pessoa do discurso.

No ato delocutivo, o resultado é uma enunciação aparentemente objetiva com retomadas de propósitos e textos que não pertencem ao locutor. Há dois casos em que isso ocorre:

i) O Propósito se impõe por si só. O locutor diz "como o mundo existe".

ii) O Propósito é um texto já produzido por outro locutor e o sujeito falante desempenha apenas a função de relator (que pode ser mais ou menos objetivo). Ele relata "o que o outro diz e como o outro diz". É o caso das diferentes formas de "Discurso relatado": citado (citação), integrado, narrativizado e evocado (alusão). Como exemplo do discurso relatado temos: “- [...] Narizinho conta que pílula era muito forte de modo que fiquei falando demais. [...]" (LOBATO, 1994a, p. 11). 


\section{REVISTA DA ABRALIN}

Como procuramos mostrar, no modo enunciativo, o enunciador organiza as categorias de língua, ordenando-as de maneira que deem conta do posicionamento do sujeito do discurso, isso por meio da modalização do enunciado, que será objeto de análise da próxima seção.

\subsection{A modalização}

A modalização, segundo a Teoria Semiolinguística, "é uma categoria de língua que reúne o conjunto dos procedimentos estritamente linguísticos, os quais permitem tornar explícito o ponto de vista do locutor." (CHARAUDEAU, 2010, p. 81). Entretanto a tradição gramatical não trata a modalização como uma categoria de língua que possui existência própria e, por essa razão, os fatos de modalização são distribuídos em diferentes categorias como:

i) categorias de frases: afirmativa, negativa, interrogativa, imperativa, exclamativa;

ii) construção de modos verbais: indicativo, subjuntivo e imperativo;

iii) classificação de advérbios: dúvida, afirmação, opinião.

Segundo Charaudeau, "essa abordagem não capta o fenômeno da Modalização como um todo que corresponde a uma intenção de comunicação." (CHARAUDEAU, 1992, p. 571). É inadequado classificar as Modalidades de acordo com as formas verbais ou adverbiais, pois as marcas linguísticas não são monossêmicas: uma mesma palavra pode assumir significados diferentes ou pode expressar diferentes intenções comunicativas, dependendo da situação. Machado (2001, p. 68) cita o exemplo do verbo querer que pode exprimir uma ordem ou um pedido. Como comprova a fala de Emília "Esse papel não serve, Senhor Visconde. Quero papel cor do céu com todas a suas estrelinhas. Também a tinta não serve. Quero tinta cor do mar com todos os seus peixinho. E quero pena de pato com todos os seus patinhos." (LOBATO, 1994a, p. 8). Nessa situação de comunicação, os verbos utilizados revelam uma ordem porque ela não está importando se sua vontade pode ser realizada ou não, apenas deseja que seja cumprida, confirmando a personalidade forte e teimosa de Emília, enfatizada pela repetição do verbo querer.

A intenção comunicativa pode também ser expressa por marcas linguísticas que pertencem a sistema de formas diferentes, como no exemplo "(1) Saia daqui, vai embora!" (2) "Some!" (3) "[gesto com o dedo indicando a porta]" (MACHADO, 2001, p. 68). Assim sendo, o leitor, ao fazer a leitura do texto, seja oral ou escrito, não pode ficar preso apenas às marcas linguísticas, mas deve prestar atenção também aos gestos, entonação, expressões faciais, ou seja, a linguagem não verbal auxilia a interpretação do enunciado, por esse motivo é tão importante quanto à linguagem verbal. Exemplo disso são as descrições do narrador que ajudam a compor a cena e a complementar o 


\section{REVISTA DA ABRALIN}

comportamento de Emília com seu interlocutor Visconde. "Disse e empurrou o Visconde para fora do quarto. Tomou da pena e escreveu. (LOBATO, 1994a, p. 50).

Além disso, a modalização pode não ser expressa por uma marca linguística, mas pela organização do conjunto do enunciado como um todo, juntamente com gestos, pontuação, entonação, olhares e particularidades do contexto do enunciado. A modalização, portanto, pode encontrar-se também no implícito do discurso. Partindo dessa observação, para Machado:

[...] a Modalização é então considerada como uma categoria conceitual, que abarca diferentes meios de expressão, meios estes que permitem ao sujeito falante explicitar suas posições e intenções comunicativas. A modalização vai então se compor de certo número de atos enunciativos de base, que correspondem a uma tomada de posição particular do locutor em relação ao seu ato de locução. (MACHADO, 2001, p. 69).

Assim sendo a modalização é composta de certo número de atos enunciativos que correspondem a um comportamento específico do locutor em seu enunciado. São chamados de Atos Locutivos e as especificações desses atos, de modalidades enunciativas. Como já tratado na seção anterior, devemos considerar três tipos de atos locutivos conforme a posição assumida pelo locutor: alocutivo, elocutivo e o delocutivo. ${ }^{5}$

Cada um desses atos tem características e finalidades próprias. As especificações desses atos são denominadas como modalidades enunciativas que podem se manifestar, segundo Charaudeau (1992), de diversas formas:

- por meio de marcas formais explícitas que podem ser:

i) verbos como: "eu acho que", "eu tenho que", "confesso que", "duvido que", que podem se manifestar nos modos verbais indicativo, subjuntivo e imperativo.

ii) advérbios e locuções adverbiais como: "sem dúvida", "talvez", "provavelmente", "no meu ponto de vista", "verdadeiramente", etc.

iii) adjetivos em construções pessoais como: "é lindo", "é terrivel", "é espantoso", ou impessoais como: "é surpreendente que", "é duvidoso que", que se combinam com os modos verbais indicativo, subjuntivo e imperativo.

iv) o uso da entonação e pontuação que dará, conforme o enunciado, o tom de uma forma imperativa, interrogativa ao ato.

5 De acordo Charaudeau (2014, p. 309-310) “[...] O alocutivo caracteriza-se pelo fato de que 'o locutor implica o interlocutor em seu ato de enunciação e lhe impõe o conteúdo de seu propósito' (1992: 574); o elocutivo caracteriza-se pelo fato de que 'o locutor situa seu propósito em relação a ele mesmo' (1992: 575); o delocutivo caracteriza-se pelo fato de que 'o locutor deixa que o propósito se imponha como tal, como se ele não fosse responsável por ele' (1992: 575).” 


\section{REVISTA DA ABRALIN}

- pela organização particular do contexto, vinculada à situação de comunicação. Nesse caso, a modalidade enunciativa pode não ser expressa por nenhuma marca linguística específica, inserindo-se no implícito do discurso que, por sua vez, depende da situação de comunicação.

Na sequência, serão apresentadas as descrições e análises dos atos locutivos do corpus na seguinte ordem: atos alocutivos, elocutivos e delocutivos, tendo em vista que a análise das categorias será feita nessa ordem, considerando a relação de influência entre Emília e os interlocutores.

\section{Análise do modo enunciativo}

\subsection{Procedimentos linguísticos alocutivos}

O desejo da boneca em iniciar suas memórias era imenso, porém ela não gostava de escrever com suas mãos, portanto corre ao encontro do Visconde para que esse pudesse escrever por ela. Como já sabemos, Emília é uma boneca de trapo, de macela e cheia de vontades. Os verbos no imperativo sinalizam a personalidade autoritária da boneca construída na e pela narrativa, uma vez que todas as suas vontades têm de ser cumpridas de qualquer forma. Nesta seção, iremos analisar, separadamente, as interações entre Emília e Visconde, entre Emília e tia Anastácia e entre a boneca e anjinho.

\subsubsection{Emília e Visconde}

Logo no início da narrativa, Emília chama Visconde e ordena-lhe que seja seu secretário. Considerando a análise dos dados dos diálogos entre esses dois personagens, das duzentas e setenta e quatro palavras ou expressões modalizadoras, cento e seis são alocutivas, indicando o ato de ordem, o que demonstra que a locutora Emília se coloca em posição de superioridade em relação ao seu interlocutor Visconde, levando-o a seguir suas ordens. Vejamos alguns trechos que ilustram essa relação:

\footnotetext{
- Visconde - Disse ela - venha ser meu secretário. Veja papel, pena e tinta. Vou começar as minhas Memórias.

O sabuguinho científico sorriu.

- Memórias! Pois então uma criatura que viveu tão pouco já tem coisas para contar num livro de memórias? Isso é para gente velha, já perto do fim da vida.

- Faça o que eu mando e não discuta. Veja papel, pena e tinta. (LOBATO, 1994a, p. 8).
} 


\section{REVISTA DA ABRALIN}

O enunciado "Faça o que eu mando e não discuta. [...]" (LOBATO, 1994a, p. 8), logo no início da história, já demonstra a personalidade mandona de Emília e seu domínio sobre o Visconde, uma vez que é ela quem manda, levando o leitor a inferir que a boneca não aceita discussão ou argumentos contra sua vontade. A ordem está dada e ela não vai mudar de ideia. Além disso, o narrador descreve uma boneca exigente, que chega a ser mal-educada com seu amigo, mas, ao mesmo tempo, muito inteligente e até voluntariosa.

As formas verbais mais significativas são: "venha ser", "veja", "faça", "não discuta" que demonstram que Visconde teria de fazer da forma como ela queria; suas memórias tinham que ser contadas à sua maneira e gosto, reforçando o que foi dito no parágrafo anterior.

São recorrentes, na obra, o uso de verbos no imperativo, expressando ordem tais como: "botar", "cortar", "pôr". Além disso, a repetição de alguns deles parece reforçar o traço impaciente, autoritário e transgressor da personagem, como pontua Khéde (1986). Além dessas modalidades, chamamos atenção para a forma como o enunciador-narrador relata os atos de fala de Emília, tais como: ordenar e danar. ${ }^{6}$ Considerando-se os significados e as circunstâncias de uma enunciação recriada artisticamente, parece que esses verbos vêm corroborar a construção da imagem de uma protagonista autoritária e prepotente, como mostra o exemplo:

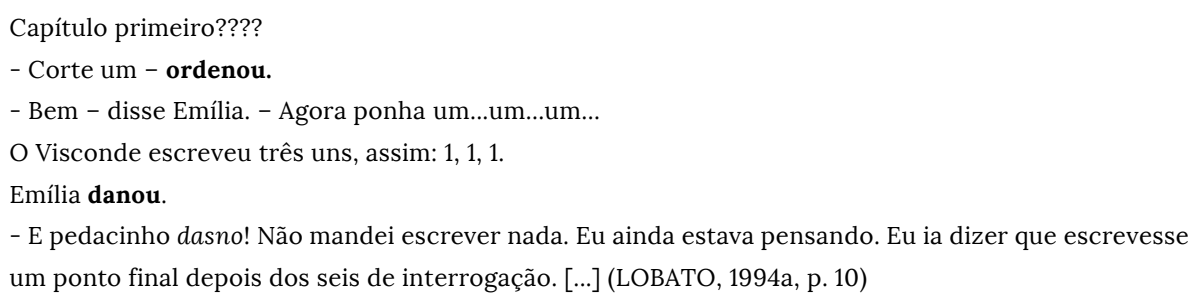

No corpus, foram identificadas onze categorias modais de opinião. Três delas contidas na passagem em que a boneca se refere a problemas sociais, como, por exemplo: (i) isso é que é o importante, (ii) ser esperto é tudo (iii) o mundo é dos espertos, em que Lobato parece, implicitamente, chamar a atenção para desigualdade social e a exploração do trabalho, ou seja, "nada mais é que uma crítica ao capitalismo, o homem como mercadoria do homem" (SANTOS; GUIRALDELLI, 2018, p. 501).

\footnotetext{
- Perfeitamente, Visconde! Isso é que é o importante. Fazer coisas com a mão dos outros, ganhar dinheiro com o trabalho dos outros, pegar nome e fama com a cabeça dos outros: isso é que é saber fazer as coisas. Ganhar dinheiro com trabalho da gente, ganhar nome e fama com a cabeça da gente, é não saber fazer as coisas. Olhe, Visconde, eu estou no mundo dos homens há pouco tempo, mas já aprendi a viver. Aprendi o grande segredo da vida dos homens na terra: a esperteza! Ser esperto é tudo. O mundo é dos espertos. Se eu tivesse um filhinho, dava-lhe um só conselho: "Seja esperto, meu filho!" (LOBATO, 1994, p. 42).
}

6 Segundo Ferreira (2000, p. 501), ordenar significa, "determinar por ordem, mandar, conferir o sacramento da ordem, pôr em ordem, arranjar, dispor". A palavra danar, por sua vez, significa "encolerizar-se, sair-se mal, dançar" (FERREIRA, 2000, p. 202). 


\section{REVISTA DA ABRALIN}

Na percepção de Silveira \& Schneider (2013), a resposta de Emília é um exemplo claro dessa representação do sistema explorador, conforme pode ser observado na interação da boneca com o Visconde quando ele lhe indaga se ela sabe escrever memórias, em clara crítica estabelecida ao fato de não consistir exatamente em escrever memórias sobre si quando se escreve com a mão e a cabeça dos outros.

A voz que aparece aqui está chamando a atenção para o que é capitalismo: ganhar dinheiro com o trabalho dos outros, criticando, assim, o que acontece em um sistema em que se explora a mão de obra alheia.

A categoria modal de interpelação também é recorrente no corpus, uma vez que a locutora Emília destaca Visconde entre os demais, designando-o sempre pelo nome, deixando claro com quem estava falando, como ocorre nessa passagem "- É que o começo é difícil, Visconde. Há tantos caminhos que não sei qual escolher. Posso começar de mil modos. Sua ideia qual é?" (LOBATO, 1994a, p. 10).

Foram identificadas vinte e oito interpelações, porém seis são precedidas pelo pronome de tratamento "senhor" que é utilizado em situações de comunicação em que o interlocutor exige formalidade e respeito, no entanto, no corpus analisado, esse pronome parece revelar que Emília assume uma posição de superioridade em relação ao seu interlocutor, como demonstra esta fala da personagem:

\footnotetext{
- Pois eu não me estreparei. A vida, Senhor Visconde, é um pisca-pisca. A gente nasce, isto é, começa a piscar. Quem pára de piscar, chegou ao fim, morreu. Piscar é abrir e fechar os olhos - viver é isso. É um dorme-e-acorda, e dorme-e-acorda, até que dorme e não acorda mais. É portanto um pisca-pisca. (LOBATO, 1994a, p. 11).
}

Essa relação de superioridade confirma o autoritarismo e até mesmo uma certa ousadia da personagem, devido ao fato de ela considerar que tem mais conhecimento do que o gênio da ciência, e não seria uma explicação sobre a vida que iria deixá-la atrapalhada, pois, sendo ela tão sábia e filosófica, Visconde deveria ter respeito e dedicação por ela.

Apesar de Emília pensar que pode ter mais conhecimento, ou ser melhor do que Visconde, ela sempre quer saber alguma informação sobre o relato de suas memórias, reforçando, mais uma vez, sua autoridade sobre o sabugo. Assim sendo, no corpus, foram contabilizadas vinte e três ocorrências dessa categoria. Na passagem a seguir, Emília começa a fazer perguntas a Visconde, obrigando-o a atender o seu desejo.

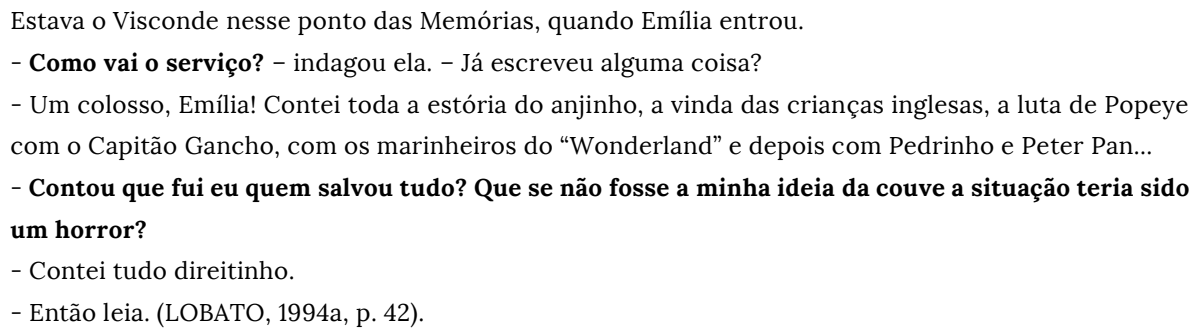

As categorias de interpelação e de interrogação são recorrentes porque a obra se constrói de forma dialogada, portanto são constitutivas do modo de narrativa escolhido. 


\section{REVISTA DA ABRALIN}

Uma categoria que não aparece frequentemente é a de sugestão, apenas quatro ocorrências foram contabilizadas no corpus. No capítulo em que Visconde começa a escrever as memórias de Emília, Quindim a chama para brincar e ela dá as ordens para seu secretário continuar escrevendo sozinho, como exemplifica a passagem a seguir:

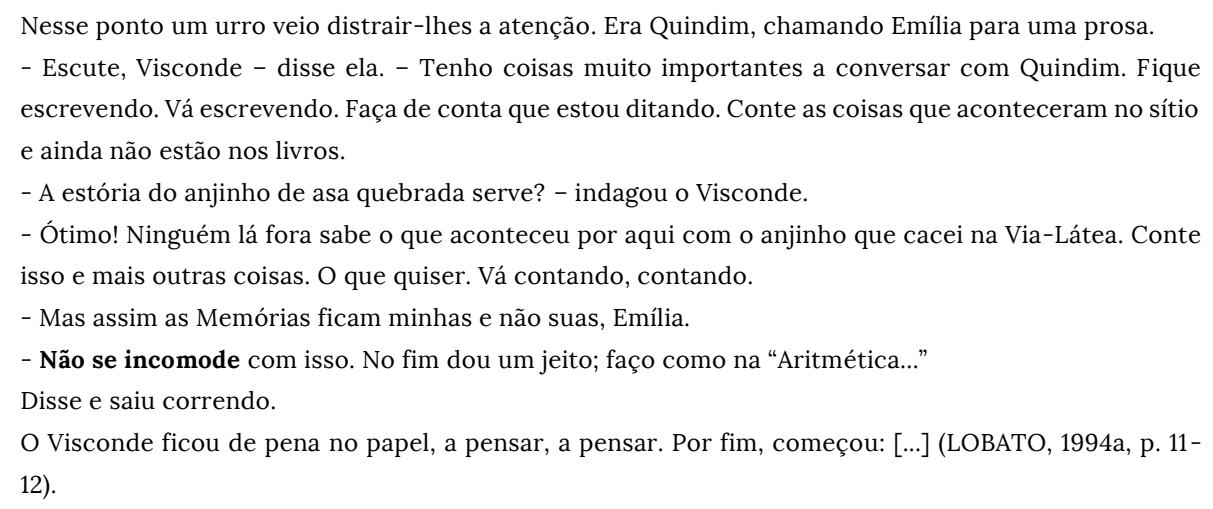

Ao ser questionada sobre a autoria das memórias, a boneca não se abala, apenas sugere que ele não se incomode, isso porque já estava acostumada a usá-lo ou, até, trapaceá-lo. Em se tratando do livro Aritmética da Emília, quem teve a ideia de escrevê-lo e o escreveu foi Visconde, mas Emília o traiu porque ela entrou em seu escritório e, viu que, no manuscrito do livro Aritmética do Visconde, na palavra Aritmética, o traço da letra T não tinha sido colocado. Ela corrigiu a grafia da letra T e substituiu o nome do verdadeiro autor, pelo próprio. Assim sendo, o livro ficou intitulado Aritmética de Emília.

Ao ter essa atitude, ela usou de sua esperteza para não ter trabalho de escrever e ainda ficar, consequentemente, com a fama. Portanto ela quer fazer, novamente, o que já havia feito e sugeriu que ele não se incomodasse, pois, no fim daria um jeito, mesmo que isso não fosse o mais honesto.

Na próxima seção, serão analisados os procedimentos alocutivos empregados nos diálogos com tia Nastácia, representante de uma classe social desprivilegiada, por ser negra, humilde e analfabeta.

\subsubsection{Emília e Tia Nastácia}

A interação entre essas duas personagens parece indicar que o autor reforçou estereótipos que dizem respeito à maneira preconceituosa como os negros eram tratados naquela época, porque tia Nastácia aparece na história sempre cozinhando, ou fazendo os serviços domésticos, embora houvesse manifestações de afeto e carinho entre ela e demais pessoas do sítio.

No corpus, foi possível observar que a interrogação foi a modalidade alocutiva mais recorrente, reforçando a imagem de uma boneca questionadora. Nessa passagem, Emília fica enfurecida com tia Nastácia e a questiona sobre as consequências de seus atos.

Só Emília não chorou. Apenas enfureceu-se contra tia Nastácia.

- Aquela burrona! Prometeu que cortava a asinha dele e não cortou. Agora, está aí... 


\section{REVISTA DA ABRALIN}

Foi correndo à cozinha tomar satisfações.

- Viu o que a senhora fez? Por causa da sua lerdeza, do seu medo, do tal 'sacrilégio', perdemos o nosso anjinho. Voou! Foi-se para sempre...

Nastácia enxugou uma lágrima na ponta do avental.

- Mas eu não tinha coragem de cortar a asinha dele, Emília. Tive[J1] medo. Essas criaturinhas do céu são as aves de Deus. Deus podia me castigar...

- Castigar, nada! - berrou Emília - Todas as aves são de Deus e no entanto prendemos canários e sabiás nas gaiolas e comemos pombos assados sem que Deus se importe. Pensa que Ele fica o tempo todo prestando atenção nas aves do quintal do céu? Tem mais o que fazer, boba. [...] Burrona! Negra beiçuda! Deus que te marcou, alguma coisa em ti achou. Quando ele preteja uma criatura é por castigo. (LOBATO, 1994a, p. 45).

Emília confirma mais uma vez o "potencial transgressor" de que fala Khéde (1986), ao desafiar a crença religiosa da tia Nastácia, dizendo que Deus não perderia tempo prestando atenção no que a empregada estava fazendo porque tinha outros afazeres. Mencionando as atitudes de Deus, ela rompe com os posicionamentos de uma criança e, ao proferir ofensas contra tia Nastácia, demonstra o seu lado perverso, rompendo, assim, com o imaginário sociodiscursivo de que as crianças são inocentes e despidas de malícias.

Ao ficar furiosa com tia Nastácia, a boneca reforça estereótipos da raça, insistindo na sua insignificância com intenção de ofender a personagem negra e humilhá-la. Para isso, utiliza alguns substantivos e adjetivos, como burrona, negra beiçuda, nariz chato e completa dizendo que, se Deus a marcou com aquela cor, foi porque ela cometeu algum pecado. Com essas palavras, a boneca declara e confirma o preconceito que havia na sociedade da época em relação aos negros.

A seguir, serão analisados os procedimentos alocutivos das interlocuções de Emília e anjinho, personagem divino, caracterizado como um ser inocente e puro.

\subsubsection{Emília e anjinho}

O capítulo em que Visconde narra a história do anjinho revela uma outra face da boneca. Emília mostra-se uma pessoa atenciosa, dedicada e, principalmente, delicada com esse ser angelical. Na passagem abaixo, observamos dois momentos em que a boneca usa os verbos no imperativo, mas com paciência e sem perder o controle da situação.

\footnotetext{
- 'Árvore, sabe o que é?'- perguntava ela.

- Árvore - dizia- é uma pessoa que não fala; que vive sempre de pé no mesmo ponto; que em vez de braços tem galhos; que em vez de unhas tem folhas; que em vez de andar falando da vida alheia e se implicando com a gente (como os tais astrônomos), dão flores e frutas. Umas dão pitangas vermelhas; outras dão laranjas doces ou azedas - e é destas que tia Nastácia faz doces; outras como aquela enorme ali (as lições eram sempre no pomar) dão umas bolinhas pretas chamadas jabuticabas. Vamos, repita: ja-bu-ti-ca-ba...'

$[\ldots]$

- 'Machado é o mudador das árvores - muda a forma delas, fazendo que o tronco e os galhos fiquem curtinhos. Muda-lhes até o nome. Árvore machadada deixa de ser árvore. Passa a ser lenha. Le-nha. Repita.' (LOBATO, 1994a, p. 12).
} 


\section{REVISTA DA ABRALIN}

Vale observar que, nessas duas passagens anteriores, tamanha é a paciência da boneca que ela chega a soletrar as palavras para que ele entenda perfeitamente a pronúncia e aprenda a falar como as pessoas da terra, e saiba, inclusive, como são e para que são usadas.

A marca de modalidade alocutiva mais recorrente e que nos ajuda a observar essa dedicação e paciência da boneca é a de interrogação, porque ela estava dando aulas para o anjinho, portanto fazialhe várias perguntas retóricas, provavelmente para dinamizar a situação e, como ele não sabia responder a elas, ela dava as respostas e explicava-lhe, minuciosamente, cada dúvida sobre o assunto.

\footnotetext{
- Cortar a língua? Essa palavra língua quer dizer duas coisas: um órgão da boca, onde está localizado o paladar e também a fala dos homens. Há línguas do Rio Grande, que vêm em latas e servem para comermos e há as línguas da falação - a língua latina, a grega, a portuguesa, a inglêsa. Estas não servem para comer - só para armar bate-boca... (LOBATO, 1994a, p. 13).
}

A maneira como a boneca trata o anjinho, mais uma vez, confirma sua dedicação. Nas duas vezes em que aparece a categoria modal de interpelação, nota-se que ela se dirige a ele com carinho e afeto, chamando-o pelo nome de "anjinho" e "Flor", sendo que essa última forma aparece pela primeira vez na história quando Visconde narra a maneira como esse ser angelical foi resgatado do céu e descreve como era lindo, denominando-o como florzinha das alturas.

\footnotetext{
- Todo o mal vem da língua - afirmava a boneca. - E para piorar a situação existem mil línguas diferentes, cada povo achando que a sua é a certa, a boa, a bonita. De modo que a mesma coisa se chama aqui dum jeito, lá na Inglaterra de outro, lá na Alemanha de outro, lá na França de outro. Uma trapalhada infernal, anjinho. (LOBATO, 1994a, p. 14).
}

Nessa encenação entre Emília e anjinho, por meio das expressões dum jeito e uma trapalhada, podemos observar que Lobato optou pelo uso de uma linguagem descontraída e mais próxima do público-alvo, bem diferente daquela utilizada nas histórias infantis da época, que eram escritas na linguagem padrão e não atraiam os pequenos leitores. Parece que o autor queria mostrar ao seu público os vários significados de uma mesma palavra, portanto no capítulo II, do livro Memórias de Emília não só narrava as histórias do anjinho de asa quebrada, como também se preocupava em aumentar o vocabulário das crianças, cumprindo assim uma função didática dentro da obra.

Apresentados exemplos de procedimentos linguísticos alocutivos na interação de Emília com seus interlocutores, passaremos a analisar separadamente os procedimentos linguísticos elocutivos também extraídos dos diálogos da boneca.

\subsection{Procedimentos linguísticos elocutivos}

De acordo com Charaudeau (2010), nas modalidades elocutivas, o locutor expressa seu ponto de vista sem implicar o interlocutor, modalizando subjetivamente o enunciado por meio de algumas categorias já mencionadas anteriormente na seção sobre o Modo Enunciativo. 


\section{REVISTA DA ABRALIN}

\subsubsection{Emília e Visconde}

Para interagir com Visconde, Emília recorre a algumas modalidades elocutivas constatação, recusa, ignorância, possibilidade, discordância, apreciação, querer, saber e opinião, sendo a con statação a categoria mais utilizada pela personagem. A utilização dessa categoria parece indicar que a enunciadora reforça a imagem de uma personagem que tinha segurança e confiava no que dizia, sem precisar da aprovação de outra pessoa. Nas interações com Visconde, o próprio sabugo confirma as afirmações da boneca, ou a ajuda, concordando com suas hipóteses, como comprova a passagem a seguir:

\footnotetext{
- O Senhor me traiu. Escreveu aqui uma porção de coisas perversas e desagradáveis, com o fim de me desmoralizar perante o público. Mas, pensando bem, vejo que sou assim mesmo. Está certo. Leu mais uma vez o capítulo.

- É isso mesmo. Sou tudo isso e ainda mais alguma coisa. Pode ficar como está. Cada um de nós dois, Visconde, é como tia Nastácia nos fez. Se somos assim ou assados, a culpa não é nossa - é da negra beiçuda. (LOBATO, 1994a, p. 50).
}

No fragmento a seguir, ela discorda da opinião de Visconde, que a comparou a uma mulher, dizendo que ela fala mais que qualquer mulherzinha. Lobato, ao utilizar a palavra mulher no diminutivo, reforça o machismo existente na época, que exigia submissão e obediência feminina, primeiramente aos pais e, depois, aos maridos:

\footnotetext{
- Tenha paciência, Emília - disse o Visconde. - Ficou muito acima do nível, porque a verdade é que você ainda hoje fala mais do que qualquer mulherzinha.

- Mas não falo pelos cotovelos, como elas. Só pela boca. E falo bem. Sei dizer coisas engraçadas e até filosóficas. Inda há pouco Dona Benta declarou que eu tenho coisas de verdadeiro filósofo. Sabe o que é filósofo, Visconde? (LOBATO, 1994a, p. 11).
}

De acordo com Gomes esse preconceito do sabugo é observado em um texto lobatiano que fala sobre palestras femininas:

Palestra é modo de dizer; numa audição é o certo, porque as mulheres, no geral, não conseguem manter o tom da conversação equilibrado no ritmo alternativo do 'fala um, responde outro'. Nada disso. O que elas querem é falar. Falar por falar. Falar a todo o transe (...) até à exaustão. (GOMES, 2014, p. 6-7).

Vale lembrar que quem filosofa aqui é uma boneca falante, um projeto, um vir a ser. Por transitar livremente entre os dois mundos, real e fictício, não ser mulher de verdade lhe dá o direito de dizer o que pensa, sem sofrer as sanções previstas pela sociedade. Além do mais temos de considerar que quem registrou essa fala foi Visconde - gênero masculino.

Emília, porém, perspicaz e decidida, foi logo argumentando e justificando seus possíveis defeitos com a categoria de apreciação, na qual, conforme Charaudeau explica, "[...] o locutor avalia não mais a verdade do propósito, mas seu valor, revelando seus próprios sentimentos. [...]" 


\section{REVISTA DA ABRALIN}

(CHARAUDEAU, 2010, p. 93) o que pode ser exemplificado por: "- Mas não falo pelos cotovelos, como elas. Só pela boca. E falo bem." (LOBATO, 1994a, p. 11).

Ao iniciar o enunciado com o conectivo mas, Emília está refutando a qualidade da sua fala, ou seja, não fala sem pensar, sem raciocinar sobre o assunto. Ela quer levar o leitor a entender que é inteligente, que sabe abordar assuntos necessários e importantes para a sociedade. E a boneca marca essa diferença: Eu sou eu e não falo como as mulheres.

Embora a categoria de recusa apareça apenas uma vez, a passagem seguinte demonstra que quem dita as regras dentro da história é a boneca, pois, se não for do seu jeito, não há acordo. "Então não escrevo! - disse Emília." (LOBATO, 1994a, p. 8), comprovando a resistência em aceitar o que lhe era sugerido pelo Visconde. É principalmente na interação com Visconde que Emília mostra a sua inteligência e sua personalidade forte ao dominá-lo, sem que ele possa reagir. Ela traduz o universo do que é ser criança real, capaz de afrontar um adulto.

Vejamos a seguir algumas passagens dos procedimentos elocutivos usados pelo autor para caracterizar a personagem Emília na interação com a personagem que representa a empregada doméstica na história do Sítio do Picapau Amarelo.

\subsubsection{Emília e tia Nastácia}

Emília, ao interagir com tia Nastácia, utiliza duas categorias da modalidade elocutiva que são a constatação e a apreciação. No corpus analisado, foram identificadas quatorze palavras ou expressões que fazem parte da categoria da constatação, pois Emília, ao produzir o enunciado, não implica a sua interlocutora naquilo que diz, apenas expressa o seu ponto de vista. Prova disso está na passagem abaixo em que a boneca intimida tia Nastácia a cortar a asa do anjinho e ela recusa-se por achar que seria cometer um pecado, uma vez que os anjos do céu são sagrados, portanto não podem ser violados.

Diante da resposta da tia Nastácia, Emília decide cortar a asa do anjinho por constatar que ele estaria mudado. Ao identificar essa mudança, Emília prevê, pela atitude do pequeno, que ele estaria pensando em fugir, já que sua asa estava curada e poderia voar sem nenhum problema.

\footnotetext{
Emília foi e intimou a preta a cortar a asa do anjinho naquele mesmo dia.

- Deus me livre! - respondeu tia Nastácia. - Cortar a asa dum anjo do céu, como se fosse galinha?... Deus me livre de cometer semelhante sacrilégio. Os anjos São criaturas celestes.

- - Pois então eu mesma corto - gritou Emília. - Ele está mudado e hoje me deu um abraço e um beijo com cheirinho de despedida. E já voa perfeitamente, sabe? (LOBATO, 1994a, p. 44).
}

Nessa resposta, ainda identificamos a categoria de apreciação "com cheirinho de despedida" por considerar, de acordo com Charaudeau (2010, p. 93), que [...] o locutor avalia não mais a verdade do propósito, mas seu valor, revelando seus próprios sentimentos. [...]". Emília não tinha certeza da intenção do anjinho de fugir, apenas suspeitou pela forma como ele agia, uma vez que a abraçou e beijou, formas usadas como cumprimentos de despedidas. 


\section{REVISTA DA ABRALIN}

Na próxima seção, serão analisados os procedimentos elocutivos utilizados na fala da boneca para interagir com anjinho, personagem que Emília resgata do céu em uma de suas aventuras do livro Viagem ao céu, publicado em 1932.

\subsubsection{Emília e anjinho}

A história de Emília com anjinho foi curta, mas intensa. Tudo começou quando as crianças do sítio foram para mais uma de suas aventuras, agora no céu. História escrita por Lobato na qual as crianças tiveram a ideia de usar o pó de pirlimpimpim para excursionar pela galáxia, onde conheceram São Jorge e visitaram outros planetas.

Emília, no entanto, não desceu do céu sozinha; junto com ela veio também um anjinho que, lá, encontrou triste e de asa quebrada. No capítulo II, de Memórias de Emília, em que Visconde o descreve como mimoso, lindo e galante, Emília torna-se sua professora, pois o anjinho mostrou-se ignorante em relação às coisas da terra, portanto, de certa forma, torna-se responsável por ele. Com todo esse empenho da boneca, a categoria modal mais encontrada no corpus foi a constatação, com cento e trinta e nove ocorrências. Essa categoria revela que não há uma implicação subjetiva do locutor, uma vez que observa os fatos objetivamente, como comprova a citação seguinte.

\footnotetext{
- Mas por que essas tais árvores nunca saem do mesmo lugar?

- Porque têm raízes - explicava a Emília. - Raiz é o nome das pernas tortas que elas enfiam pela terra adentro. Bem que querem andar, as pobres árvores, mas não conseguem. Só saem do lugarzinho em que nascem quando surge o machado. (LOBATO, 1994a, p. 12).
}

Nessa passagem, há alguns exemplos de palavras que demonstram que Emília tem conhecimento sobre o assunto tratado, como qualquer professora que gostaria de transmitir um conhecimento ou tirar dúvidas de seu aluno e, por mais que a boneca goste de opinar e ache que sabe mais que muitas pessoas, ela não dá a sua opinião, apenas explica ao anjinho sobre o que ele não conhecia, isso tudo com muita paciência e dedicação.

Emília, conforme Lajolo (2001), revela-se uma boneca loquaz e desbocada, que, após conquistar sua liberdade por meio da fala, emite suas opiniões sobre determinados assuntos que não eram considerados próprios para as crianças. Na análise do corpus, há uma ocorrência de vinte e uma categorias modais de opinião, o que a torna a segunda categoria da modalidade elocutiva mais utilizada no corpus selecionado. Nessa categoria, segundo Charaudeau (2010, p. 92), "[...] o locutor, avalia a verdade de seu propósito e, ao mesmo tempo, revela qual é o seu ponto de vista." A verdade do propósito e o ponto de vista são elementos fundamentais para construção do discurso de Emília.

O propósito do autor, ao utilizar essa categoria, foi, provavelmente, fazer com que a boneca emitisse seu ponto de vista sobre determinados assuntos que envolviam a sociedade da época e que poderiam ser discutidos não só pelas crianças, mas também pelos adultos, fazendo-os refletirem 


\section{REVISTA DA ABRALIN}

sobre o contexto político e social em que viviam. Isso porque Lobato sonhava com uma sociedade pensante, capaz de tomar decisões e achava que a solução estava nas crianças.

\footnotetext{
- Para atrapalhar a gente. Eu penso que todas as calamidades do mundo vêm da língua. Se os homens não falassem, tudo correria muito bem, como entre os animais que não falam. As formigas e as abelhas, por exemplo. Esses bichinhos vivem na maior ordem possível, com suas comidinhas a hora e a tempo - e que comidas! O mel é uma perfeição que você nem sonha! Exatinho da cor de seus cabelos, mas sem cachos: em vez de cachos tem favos. E qual o segredo da felicidade desses animaizinhos? Um só: não falam. No dia em que derem de falar, adeus ordem, adeus paz, adeus mel! A língua é a desgraça dos homens na terra. (LOBATO, 1994a, p. 13).
}

Nessa passagem, Emília expõe seu ponto de vista sobre o uso da língua e explica ao anjinho, que, se o mundo dos homens não é perfeito igual ao dos animais, é porque adquiriram a capacidade de falar. Apenas o homem foi capaz de adquirir o poder da linguagem durante a sua evolução, porém houve um custo alto porque essa se tornou uma arma capaz de ferir mais que qualquer outro instrumento de guerra, uma vez que, por meio dela, as pessoas emitem seus pontos de vista sobre diversos assuntos, o que pode causar desentendimentos, rompimentos e até guerras entre países. Segundo Santos \& Guiraldelli (2018, p. 499):

As críticas de Emília à língua são muito fortes, pois para ela a língua e sua ambiguidade de significados são os maiores motivos dos problemas que acontecem no mundo; diante das variedades de significados das palavras é que acontece a desordem do mundo.

Uma das maneiras de transmitir a cultura de um povo é por meio da linguagem, portanto, ao dizer que a língua é a desgraça dos homens, ironicamente, Emília está ensinando-lhe uma maneira infeliz de viver, tentando, dessa forma, humanizá-lo, ou seja, tirando dele o seu estatuto de perfeição, desconstruindo assim sua imagem angelical. Por outro lado, estamos diante de um paradoxo, afinal Emília humaniza-se assim que tomou a pílula falante, ministrada pelo Dr. Caramujo. De acordo com Sousa "A partir da aquisição da fala, inicia-se o processo de desenvolvimento da personagem, [...] que acaba por aproximar cada vez mais a boneca do humano." (SOUSA, 2009, p. 93).

A ambiguidade da personalidade de Emília e de seu discurso reside, justamente, na fusão de um ser animado e n=inanimado. A fala, característica de ser animado, confere humanidade. Contudo, vinda de uma boneca, esta humanidade é relativa, de tal sorte que a ela só cabe a oscilação entre a coerência e a incoerência, o progressismo e o estereótipo, a bondade e a maldade.

Nessa seção, foram apresentados alguns procedimentos elocutivos para análise e caracterização da personagem Emília. Na próxima seção serão analisados os procedimentos delocutivos presentes no corpus.

\subsection{Procedimentos linguísticos delocutivos}

No comportamento delocutivo, conforme exposto na seção sobre o Modo Enunciativo, o locutor retoma a fala de um terceiro, apagando-se e não implicando o seu interlocutor, sendo assim uma 


\section{REVISTA DA ABRALIN}

enunciação aparentemente objetiva com retomadas de propósitos e textos que não pertencem ao locutor. Na interação de Emília com seus interlocutores, esse comportamento surge apenas na interação com Visconde, uma vez que a boneca integra em sua fala dizeres de Narizinho e dona Benta. Esse modo de relatar é denominado por Charaudeau como narrativizado, uma vez que "O discurso de origem é relatado de tal maneira que se integra totalmente, ou mesmo desaparece, no dizer daquele que relata. O Locutor de origem torna-se o agente de um ato de dizer. [...]" (CHARAUDEAU, 2010, p. 105).

\footnotetext{
- Sei como foi a história - disse o Visconde. - Você engoliu uma falinha de papagaio.

- Está errado! Narizinho teve dó do papagaio e não deixou que o matassem para tirar a falinha. Fiquei falante com uma pílula que o célebre Doutor Caramujo me deu. Narizinho conta que pílula era muito forte de modo que fiquei falando demais. Assim que abri a boca, veio uma torrente de palavras que não tinha fim. Todos tiveram de tapar os ouvidos. E tanto falei que esgotei o reservatório. A fala então ficou no nível. (LOBATO, 1994a, p. 11).
}

Nesse diálogo com Visconde, Emília relata fatos contados por Narizinho, que aconteceram na primeira história escrita por Lobato para crianças, Reinações de Narizinho, quando conhece o Dr. Caramujo, célebre médico do Reino das Águas Claras, o qual possui pílulas que curam qualquer tipo de doença, entre elas a pílula falante. Desse modo, leva a boneca ao seu consultório e oferece-lhe a pílula que lhe dá o dom da palavra e, juntamente com a linguagem, a sua liberdade. Ao tomar a pílula, Emília começou a falar demais, por isso Narizinho sugeriu ao doutor que seria melhor fazê-la vomitar a pílula. Ele argumenta que depois a boneca se cansaria e ficaria como toda gente, no entanto isso não aconteceu, Emília tornou-se uma boneca falante e de uma língua bem afiada.

Nesta fala, parte dela já anteriormente explorada, Emília retoma o que Dona Benta disse quando conta para Visconde uma declaração da matriarca do sítio:

\footnotetext{
- Mas não falo pelos cotovelos, como elas. Só pela boca. E falo bem. Sei dizer coisas engraçadas e até filosóficas. Inda há pouco Dona Benta declarou que eu tenho coisas de verdadeiro filósofo. Sabe o que é filósofo, Visconde? (LOBATO, 1994a, p. 11).
}

As discussões filosóficas giravam em torno de temas polêmicos que permeavam a sociedade e incomodavam a boneca, pois eram difíceis de ser entendidos por ela. Ao fazer esses questionamentos, Emília desencadeava reflexões sobre assuntos como guerras, política, ciência, petróleo. "Os problemas são apresentados de maneira simples e clara, por vezes didática, de modo adequado à compreensão do leitor." (SANDRONI, 2011, p. 50).

Ainda de acordo com essa autora, esse aspecto é analisado por Eliana Yunes:

\footnotetext{
A obra de Monteiro Lobato oferece justamente uma interessante dualidade de produção, uma vez que dirigida intencionalmente a crianças considera as características desta faixa etária quanto a temas, interesses e linguagem, sem, contudo se descuidar do índice ficcional, articulado sobretudo através de situações originais não conformistas e da criatividade linguística (...). A ludicidade não se ausenta em nenhum momento dos trabalhos do autor, capaz de surpreender por sua linguagem, ainda hoje. Tampouco a relação catártica desaparece, e, sendo compromisso com a história, reflete a sociedade ora de modo crítico ora de forma a endossar alguns valores. (YUNES, 1982, p. 6 apud SANDRONI, 2011, p. 50-51)
} 


\section{REVISTA DA ABRALIN}

Com suas invencionices e, principalmente, com essa personagem, Monteiro Lobato encontrou uma fórmula de escrever que cativa o público infantil. Numa linguagem simples, bem-humorada e coloquial, cria, em um ambiente aconchegante, com personagens interessantes e criativas, histórias que aguçam a imaginação dos pequenos leitores.

\section{Considerações Finais}

A partir das análises desta obra de Monteiro Lobato, foi possível confirmar que Emília muda seu comportamento conforme seu interlocutor e suas intenções, pois, ao interagir com Visconde, tia Nastácia e anjinho, adota diferentes modos de agir. Essa mudança fica comprovada pela contagem, no corpus, da categoria alocutiva, (106 - Visconde / 5 - tia Nastácia / 20 - anjinho), a elocutiva (172 - Visconde / 26 - Tia Nastácia / 189 - anjinho) e delocutiva (6 - Visconde / 0 - Tia Nastácia / 1 anjinho) do Modo Enunciativo, principalmente considerando-se número de modalizadores empregados, o que nos permitiu verificar quais categorias eram mais recorrentes.

Os dados do corpus deixam explícito que Emília se mostra ousada, autoritária e impaciente com Visconde $e_{2}$ isso porque ela o domina, mesmo sendo esse personagem considerado o sábio e inteligente na história, fazendo-o cumprir todas as suas vontades, e ainda o humilha, mas "sua aliança com ele, transforma-se numa aliança com a ciência e a tecnologia”, explica Lajolo. (LAJOLO, 2001, s/p).

Ao interagir com o anjinho, Emília mostra-se paciente. Esse tipo de comportamento parece ecoar saberes que circulavam na sociedade sobre o mundo divino, tal como concebe a tradição católica: os anjos são criaturas de Deus e só fazem o bem, portanto merecem ser tratados com delicadeza e respeito.

Na interação com tia Nastácia, Emília revela-se preconceituosa e impaciente, mesmo sendo ela amável e atenciosa com a boneca. Nastácia representa, na obra, a classe simples e explorada no Brasil, principalmente no início do século XX, uma vez que é empregada doméstica, negra e analfabeta, portanto, Emília, às vezes, trata-a com rispidez e falta de educação, humilhando-a, chegando a fazer declarações ofensivas.

Lobato, ao encenar personagens, cria uma boneca que, ao adquirir o processo de humanização, por meio da linguagem, ousou transgredir e desrespeitar o lugar assegurado à criança da época, característica que lhe traz um encantamento todo especial. A ela também é dada a capacidade de inventar e de recriar situações inusitadas, usando a inteligência e o seu famoso pó de pirlimpimpim, capaz de fazer qualquer coisa, bastando a boneca desejar.

Por não ser totalmente humana, Emília tem direito de denunciar fatos relacionados ao mundo dos humanos sem sofrer as sanções legais. Desse modo, faz críticas às verdades estabelecidas, ao sistema capitalista, à crença religiosa das pessoas, entre outros assuntos considerados "proibidos", principalmente para as crianças, sem medo das punições. Prova disso é a maneira de relacionar-se com os interlocutores, sendo doce e amável, mas, ao mesmo tempo, rude e mal educada, sem deixar 


\section{REVISTA DA ABRALIN}

desaparecer o seu lado irônico, crítico e questionador. Por meio de histórias, Monteiro Lobato faz com que os leitores sejam capazes de refletir sobre a realidade social e enxergue a literatura como agente de mudanças.

\section{REFERÊNCIAS}

ANTÔNIO, Izabel Cristina Vieira. A atuação de Emília na obra de Monteiro Lobato: Memórias de Emília. Monografia. 2005. 42 f. Monografia (Especialização em Língua Portuguesa - Fenômeno Social Político) Universidade do Extremo Sul Catarinense, Criciúma, 2005. Disponível em:

<<www.bib.unesc.net/biblioteca/sumario/ 000027/000027DD.pdf>. Acesso em: 3 jun. 2014.

CHARAUDEAU, Patrick. Grammaire du sens et de l'expression. Paris: Hachette, 1992.

CHARAUDEAU, Patrick. Linguagem e discurso: modos de organização. 2. ed. São Paulo: Contexto, 2010.

COELHO, Nelly Novaes. Dicionário crítico da literatura infantil e juvenil brasileira. 2. ed. São Paulo, Quíron/Brasília, 1984.

DINIZ, Dilma Castelo Branco. Monteiro Lobato: o perfil de um intelectual moderno. Vol. 2. Belo Horizonte: s/l, 1998. Disponível em: <150.164.100.248/poslit/08...pgs/.../Dilma\%20Castelo\%20Branco.pdf>. Acesso em: 8 nov. 2014.

DUARTE, Paulo. Negros do Brasil. O Estado de São Paulo. 16 de abril de 1947, p. 5. Disponível em: www.fflch.usp.br/.../Negros\%20do\%20Brasil\%20-20Paulo\%20Duarte. Acesso em: 22 set. 2015.

FERREIRA, Aurélio Buarque Aurélio. Miniaurélio Século XXI Escolar: o minidicionário da língua portuguesa. 4. ed. Rio de Janeiro: Nova Fronteira, 2000.

GOMES, Eugênia Stela Ferreira. Carrapichos nas Memórias da Emília, de Monteiro Lobato. Revista Gatilho Revista discente do Programa de Pós-Graduação em Linguística da UFJF. Juiz de Fora, MG, Brasil, v. 3 Jun. 2019.

KHÉDE, Sônia Salomão. As polêmicas sobre o gênero. In: KHÉDE, Sônia Salomão (Org.). Literatura Infantojuvenil: um gênero polêmico. 2. ed. Porto Alegre: Mercado Aberto, 1986. p. 7-15.

LAJOLO, Marisa. Monteiro Lobato: um brasileiro sob medida. São Paulo: Moderna, 2000.

LAJOLO, Marisa. Fala mesmo, Sinhá! Fala que nem uma gente! Texto publicado em Personae . org. Lourenço Dantas Mota e Benjamin Abdalla. São Paulo: Ed. Senac. 2001 p. 119-137. Disponível em: <www.unicamp.br/iel/monteirolobato/outros/ Emíliasenac.pdf.>. Acesso em: 1 nov. 2014.

LOBATO, Monteiro. A Barca de Gleyre: quarenta anos de correspondência literária entre Monteiro Lobato e Godofredo Rangel. 6. ed. São Paulo: Brasiliense, 1955.

LOBATO, Monteiro. Viagem ao céu. 33. ed. São Paulo: Brasiliense, 1986

LOBATO, Monteiro. Emília no país da aritmética. 32. ed. São Paulo: Brasiliense, 1986b.

LOBATO, Monteiro. Memórias de Emília. 42. ed. São Paulo: Brasiliense, 1994a. 


\section{REVISTA DA ABRALIN}

LOBATO, Monteiro. O saci. 14. ed. São Paulo: Brasiliense, 1994b.

LOBATO, Monteiro. Emília no país da gramática. 39. ed. São Paulo: Brasiliense, 1994c.

MACHADO, Ida Lúcia. Breves considerações sobre índices de modalização e práticas de leitura. Caligrama. Belo Horizonte, 2001, v. 6, p. 63-67. Disponível em:

<http://www.periodicos.letras.ufmg.br/index.php/caligrama/article/view/343>. Acesso em: 31 out. 2014.

SANDRONI, Laura C. De Lobato a Bojunga: as reinações renovadas. 2.ed. Rio de Janeiro: Nova Fronteira, 2011. SANTOS, Nara Souza dos. Guiraldelli, Lisângela Aparecida. Monteiro Lobato: literatura infantil e as vozes polifônicas em Memórias de Emília. Revista Científica da Fundação Educacional de Ituverava. V. 15, n. 1, Abril, 2018. Disponível em <

http://www.nucleus.feituverava.com.br/index.php/nucleus/article/view/2765> Acesso em: 24 abr. 2020.

SILVEIRA, Éderson Luís. SCHNEIDER, Áquelle Miranda. As memórias da Emília: tessituras e efeitos de sentido produzidos nas subjetividades de representação. Entrelaces, Revista de Pós-Graduação em Letras UFC, ano 3, n. 1, jul. 2013. Disponível em: <http://www.entrelaces.ufc.br/rev_entr_anolII_n1.pdf>. Acesso em: 3 out. 2014.

SOUSA, Margarida Maria Alacoque Chaves. Emília: Potencialidade transgressora na formação de um conceito de infância. 2009. f. 172. Dissertação (Mestrado em Literatura Brasileira) - Programa de Pós-Graduação em Literatura, Universidade Federal de Minas Gerais, Belo Horizonte, 2009. Disponível em:

< https://repositorio.ufmg.br/bitstream/1843/ECAP-7RCJPQ/1/disserta_o_de_mestrado.pdf>. Acesso em: 28 abr. 2020

ZILBERMAN, Regina. Monteiro Lobato e suas fases. 2010. Disponível em:

<http://www.gelbc.com.br/pdf_revista/3609.pdf>. Acesso em: 22 jun. 2014. 